\title{
Comparison of Effectiveness between Combination of Beta-Lactam with Azyhtromycin or Levofloxacin for Adult Pneumonia Patients
}

\author{
Gina Arifah ${ }^{1}$, Eli Halimah², Rizky Abdulah² \\ ${ }^{1}$ Dr. Hasan Sadikin General Hospital, Bandung, West Java, Indonesia \\ ${ }^{2}$ Department of Pharmacology and Clinical Pharmacy, Faculty of Pharmacy, Universitas Padjadjaran, \\ Jatinangor, West Java, Indonesia
}

\begin{abstract}
Treatment for pneumonia has always been a challenge due to the difficulties in diagnosis and the growing incidence of antibiotic resistance. Beta-lactam antibiotics are the first line treatment for pneumonia. The combination of beta-lactam with other antibiotics are preferred than single antibiotic therapy. However, there was limited information regarding the effectiveness of combination between beta-lactam with either macrolides or fluoroquinolone for the treatment of pneumonia. The purpose of this study was to determine the most effective combination of antibiotics for hospitalized adults pneumonia patients. This was a cross-sectional study with prospective data collection. The data source was the medical record of the subjects. We included adult pneumonia patients hospitalized at Dr. Hasan Sadikin General Hospital during June-August 2015. We found that mean reduction of body temperature in group who received combination of a beta-lactam antibiotic and azithromycin was $1.53{ }^{\circ} \mathrm{C}$, while in levofloxacin group, the reduction was $1.22{ }^{\circ} \mathrm{C}(\mathrm{p}=0.210)$. Reduction in leukocytes and respiratory rate were 7800 and 2.29 times/minute, respectively, in the former group, while in the latter group the reduction of leukocytes and respiratory rate were 2600 and 5 times/minute. The differences were not statistically significant in both parameters $(\mathrm{p}=0.036$ and 0.149 , respectively). In conclusion, better clinical outcomes were observed in patients treated with combination of beta-lactam and azithromycin compared to combination of betalactam and levofloxacin, although the difference was not statistically significant.
\end{abstract}

Keywords: pneumonia, pneumonia therapy, combination therapy for pneumonia

\section{Introduction}

Pneumonia is an inflammation of the pulmonary parenchyma distal from the terminal bronchioles, leading to the damage of lung tissue and impairment in gas exchange. It was commonly caused by the infection of Streptococcus pneumoniae. ${ }^{1,2}$ Pneumonia is classified based on the origin of the disease, including community acquired pneumoniae (CAP) and nosocomial pneumonia or hospital acquired pneumoniae (HAP), which means that the disease is acquired when the patient is in a hospital or a health care setting. ${ }^{3}$

Corresponding author: Gina Arifah. Dr. Hasan Sadikin General Hospital, Bandung, West Java, Indonesia. Email: ginaarifaah@gmail.com

Received: 28 January 2018. Revised: 7 March 2018. Published: 23 April 2018. 
Pneumonia is the sixth leading cause of death in the United States. Economic impact associated with this disease is also substantial. Indonesia is one of the country with highest burden of pneumonia, with six million incidence of this disease. ${ }^{3}$

Treatment for pneumonia has always been a challenge due to the difficulties in diagnosis and the growing incidence of antibiotic resistance. Beta-lactam antibiotics is the first line treatment for pneumonia. The combination of beta-lactam with other antibiotics is preferred than single antibiotic therapy. However, there was limited information regarding the effectiveness of combination between beta-lactam with either macrolide or fluoroquinolone for the treatment of pneumonia. ${ }^{4,5}$

The purpose of this study was to compare the effectiveness of the most commonly used antibiotics combination for pneumonia, i.e., beta-lactam antibiotics with either azythromiycin (macrolide) and levofloxacin (fluoroquinolone).

\section{Methods}

This cross-sectional study was performed with prospective approach. The data source was the medical records of the patients. We included adult pneumonia patients hospitalized at Dr. Hasan Sadikin General Hospital during June-
August 2015, aged $\geq 18$ years, and were given combination of beta-lactam antibiotics with either azithromycin or levofloxacin for at least 5 days. Exclusion criteria were patients with incomplete medical data and patients who had concurrent respiratory disease, such as pulmonary TB and pleural effusion. The conduct of this study was approved by Health Research Ethics Committee, Faculty of Medicine, Universitas Padjadjaran.

From each medical records, information regarding demographic characteristics and the outcomes of the antibiotics treatments, such as reduction of temperature, leukocytes, and respiratory rate, were extracted. We compared the outcomes of the treatment with combination of beta-lactam antibiotics with either azythromyzin and levofloxacin. The differences of the outcomes were assessed statistically using t-test. $\mathrm{P}<0.05$ defined statistical signficance.

\section{Results and Discussion}

This study involved 17 adult pneumonia patients, consisting of 10 patients receiving treatment with a combination of betalactam antibiotics and levofloxacin, while other 7 patients used combination of betalactam antibiotics and azithromycin. Large proportion of participants are female $(64.8 \%)$. The mean age of participants in group receiving treatment with a combination of

Table 1. Characteristics of participants

\begin{tabular}{|c|c|c|c|}
\hline \multirow[b]{2}{*}{ Characteristics } & \multicolumn{2}{|c|}{ Treatment } & \multirow[b]{2}{*}{ P-value } \\
\hline & $\begin{array}{l}\text { Beta Lactam + Azythromiycin } \\
(n=7)\end{array}$ & $\begin{array}{c}\text { Beta Lactam + Levofloxacin } \\
(\mathrm{n}=10)\end{array}$ & \\
\hline \multicolumn{4}{|l|}{ Age (years) } \\
\hline Mean (SD) & $51.0(18.9)$ & $46.9(15.0)$ & 0.625 \\
\hline Range & $30-79$ & $24-67$ & \\
\hline \multicolumn{4}{|l|}{ Sex } \\
\hline Male & 4 & 2 & 0.162 \\
\hline Female & 3 & 8 & \\
\hline
\end{tabular}


Table 2. Comparison of the outcomes

\begin{tabular}{|c|c|c|c|c|}
\hline & \multirow{2}{*}{ Variables } & \multicolumn{2}{|c|}{ Observation } & \multirow{2}{*}{ P-value } \\
\hline & & Before & After & \\
\hline \multirow[t]{13}{*}{$\mathrm{I}$} & Beta-lactam + Azythromycin & & & \\
\hline & Temperature $\left({ }^{\circ} \mathrm{C}\right)$ & & & \\
\hline & Mean (SD) & $37.7(0.8)$ & $36.2(0.3)$ & 0.018 \\
\hline & Median & 37.8 & 36.0 & \\
\hline & Range & $36.5-38.7$ & $36.0-36.7$ & \\
\hline & Respiration (times/minutes) & & & \\
\hline & Mean (SD) & $25.4(4.4)$ & $23.1(3.4)$ & 0.350 \\
\hline & Median & 28 & 22 & \\
\hline & Range & $16-28$ & $20-28$ & \\
\hline & Leucocyte & & & \\
\hline & Mean (SD) & $1887(5745)$ & $10986(2990)$ & 0.018 \\
\hline & Median & 17000 & 11000 & \\
\hline & Range & $14000-31300$ & $7000-15000$ & \\
\hline \multirow[t]{13}{*}{ II } & Beta-lactam + Levofloxacin & & & \\
\hline & Temperature $(0 \mathrm{C})$ & & & \\
\hline & Mean (SD) & $37.6(0.6)$ & $36.4(0.3)$ & 0.005 \\
\hline & Median & 37.6 & 36.4 & \\
\hline & Range & $36.8-38.6$ & $36.0-36.8$ & \\
\hline & Respiration (times/minute) & & & \\
\hline & Mean (SD) & $27.6(1.6)$ & $22.6(2.3)$ & 0.005 \\
\hline & Median & 28 & 24 & \\
\hline & Range & $26-30$ & $20-26$ & \\
\hline & Leucocyte & & & \\
\hline & Mean (SD) & $12460(5889)$ & $10710(7683)$ & 0.283 \\
\hline & Median & 14500 & 9800 & \\
\hline & Rentang & $2500-19700$ & $4200-31000$ & \\
\hline
\end{tabular}

beta-lactam antibiotic and levofloxacin was 51 years, while in the azyhtromycin group, the mean age was 46.9 years. The age of all participants was in the range of 24-79. Characteristics of participants can be seen in Table 1.

Mean reduction of body temperature in group who received combination of a beta-lactam antibiotic and azithromycin was $1.53{ }^{\circ} \mathrm{C}$, while in levofloxacin group, the reduction was $1.22{ }^{\circ} \mathrm{C}(\mathrm{p}=0.210)$. Reduction in leukocytes and respiratory rate were 7800 and 2.29 times/minute, respectively, in the former group, while in the latter group the reduction of leukocytes and respiratory rate were 2600 and 5 times/minute. The differences were not statistically significant in both parameters $(p=0.036$ and 0.149$)$.

Treatment with pneumonia is challenging, considering difficulties in determining etiology and growing incidence of antibiotic resistance. The proper antibiotic treatment is important to reduce clinical burden associated with pneumonia. The beta-lactam antibiotics are the first-line therapy of pneumonia for over four decades. However, the growing 
Table 3. Comparison of outcomes improvement

\begin{tabular}{|c|c|c|c|}
\hline \multirow{3}{*}{ Variables } & \multicolumn{2}{|c|}{$2-$} & \multirow{3}{*}{ P-value* } \\
\hline & $\begin{array}{l}\text { Beta-lactam + } \\
\text { Azythromycin }\end{array}$ & $\begin{array}{c}\text { Beta-lactam + } \\
\text { Levofloxacin }\end{array}$ & \\
\hline & $(n=7)$ & $(n=10)$ & \\
\hline Temperature $\left({ }^{\circ} \mathrm{C}\right)$ & & & 0.210 \\
\hline Mean (SD) & $1.53(0.91)$ & $1.22(0.63)$ & \\
\hline Median & 1.3 & 1.15 & \\
\hline Range & $0.5-2.7$ & $0.5-2.5$ & \\
\hline Respiration (time/minute) & & & 0.149 \\
\hline Mean (SD) & $2.29(7.25)$ & $5.0(2.87)$ & \\
\hline Median & 6 & 4 & \\
\hline Range & $(-) 8-12$ & $2-10$ & \\
\hline Leukocytes & & & 0.036 \\
\hline Mean (SD) & 7886 (5033) & 1750 (7167) & \\
\hline Median & 7800 & 2600 & \\
\hline Range & 2000-17300 & (-) 13900-12100 & \\
\hline
\end{tabular}

incidence of resistance in the common respiratory pathogen could hinder the optimal treatment for pneumonia. Pneumonia treatment guideline often recommends the use of a macrolide, such as azithromycin, or fluoroquinolone, such as levofloxacin, in conjunction with, or as an alternative to, beta-lactam agents. However, which the most effective treatment for pneumonia is remain uncertain. ${ }^{6,7}$ Our study showed that the combination of beta-lactam antibiotics with either azythromiycin or levofloxacin resulted in the improvement of the clinical outcomes., with better reduction of leukocytes and body temperature were observed in the azithromycin group.

Azythromycin belongs to a macrolide antibiotic class which works by inhibiting the protein synthesis which is essential for multiplication and growth of bacteria. It is a broad spectrum antibiotics which is usually used to treat infections of the upper and lower respiratory tract, skin, and middle ears. Previous studies showed that the combination of macrolides to initial beta-lactam antibiotic regimen provided the protective effect against in-hospital mortality. ${ }^{8}$ Levofloxacin is the latter generation of fluoroqionolon which is particularly important to treat respiratory infection. It works by inhibiting DNA gyrase enzymes, which inhibits relaxation of supercoiled DNA and promotes breakage of double stranded DNA. ${ }^{9,10}$

Our finding was different with other study showing that combination of fluoroquinolone with beta-lactam antibiotics produced better therapeutic outcomes than combination with macrolides. ${ }^{11}$ Further investigation should be conducted, particularly with bigger sample size to generate more power to compare the effectiveness. In contrast, in this study, the higher reduction in leukocytes, respiratory rate, and body temperature were observed in patients treated with beta-lactam and azithromycin compared to levofloxacin, although the difference was not statistically significant. In this study, the prevalence of macrolide-resistant strain might be lower than that of previous study, which might affect the findings. 


\section{Conclusion}

Better clinical outcomes were observed in patients treated with combination of betalactam and azithromycin compared to combination of beta-lactam and levofloxacin, although the differences were not statistically significant.

\section{Acknowledgements}

None.

\section{Funding}

None.

\section{Conflict of Interest}

None declared

\section{References}

1. Kosar F, Alici DE, Hacibedel B, et al. Burden of community-acquired pneumonia in adults over 18 years of age. Human Vaccines \& Immunotherapeutics. 2017;13(7):1673-1680.

2. Mertz D, Johnstone J. Modern management of community-acquired pneumonia: is it cost-effective and are outcomes acceptable? Current Infectious Disease Report. 2011; 13(3):269-77.

3. Tschernig T. Hospital-acquired pneumonia and community-acquired pneumonia: two guys? Annals of Translational Medicine. 2016;4(Suppl 1):S22.

4. Tessmer A, Welte T, Martus P, et al. Impact of intravenous beta-lactam/macrolide versus beta-lactam monotherapy on mortality in hospitalized patients with community-acquired pneumonia. Journal of Antimicrobial Chemotherapy. 2009;63: 1025-1033.

5. Pakhale S, Mulpuru S, Verheij TJ, et al. Antibiotics for community-acquired pneumonia in adult outpatients. Cochrane Database Systematic Review.
2009;7(4):2109

6. Rodrigo C, Tricia MM, Mark W, et al. Single versus combination antibiotic therapyin adults hospitalised with community acquired pneumonia. Chest Clinical Thorax. 2013;68:493-495

7. Adrie $\mathrm{C}$, Carole $\mathrm{S}$, Maite $\mathrm{GO}$, et al. Initial use of one or two antibiotics for critically illpatients with communityacquired pneumonia: impact on survival and bacterial resistance. Critical Care. 2013; 17:R265

8. Caballero J, Jordi R. Combination antibiotic therapy for community acquired pneumonia. Annals of Intensive Care. 2011;1:48.

9. Gaillard T, Dormoi J, Madamet M, et al. Macrolides and associated antibiotics based on similar mechanism of action like lincosamides in malaria. Malaria Journal. 2016;15:85.

10. Ferrándiz MJ, de la Campa AG. The fluoroquinolone levofloxacin triggers the transcriptional activation of iron transport genes that contribute to cell death in Streptococcus pneumoniae. Antimicrobial Agents and Chemotherapy. 2014;58(1):247-257.

11. Drago L, Nicola L, Rodighiero V, et al. Comparative evaluation of synergy of combinations of beta-lactams with fluoroquinolones or a macrolide in Streptococcus pneumoniae. Journal of Antimicrobial Chemotherapy. 2011;66:845-849. 